\title{
Swimming starfish, a departing dinosaur and a lot of ice
}

The sharpest science shots from December and January, selected by Nature's photo team.

Daniel Cressey

27 January 2017

After spending December producing our pictures of the year, Nature's images of the month returns with a bumper round up of the best images and videos from the past two months.

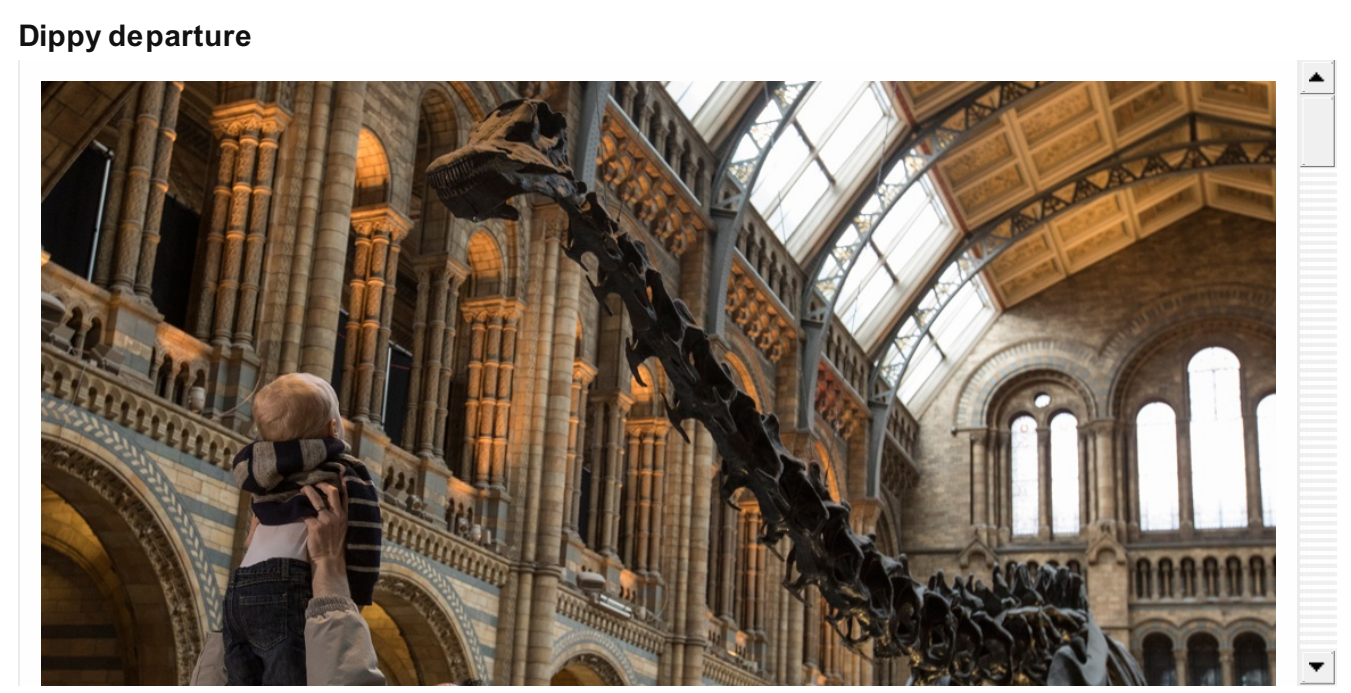

\section{Aerial arctic}

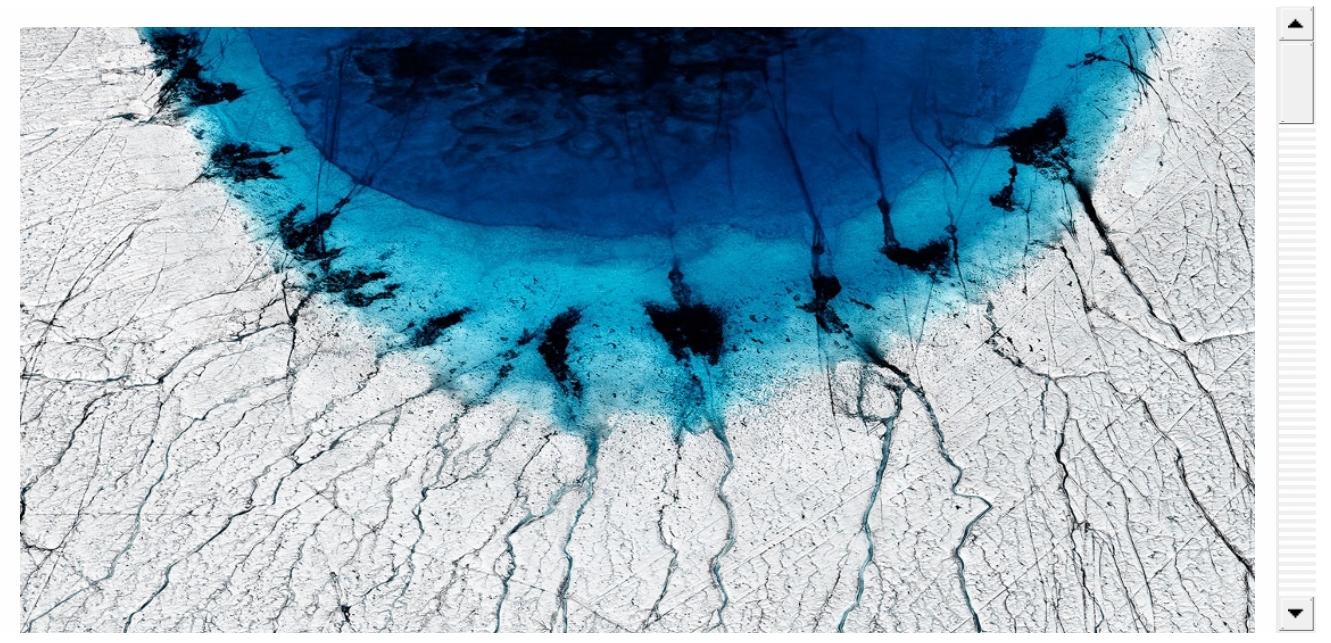

Shifting sheds 


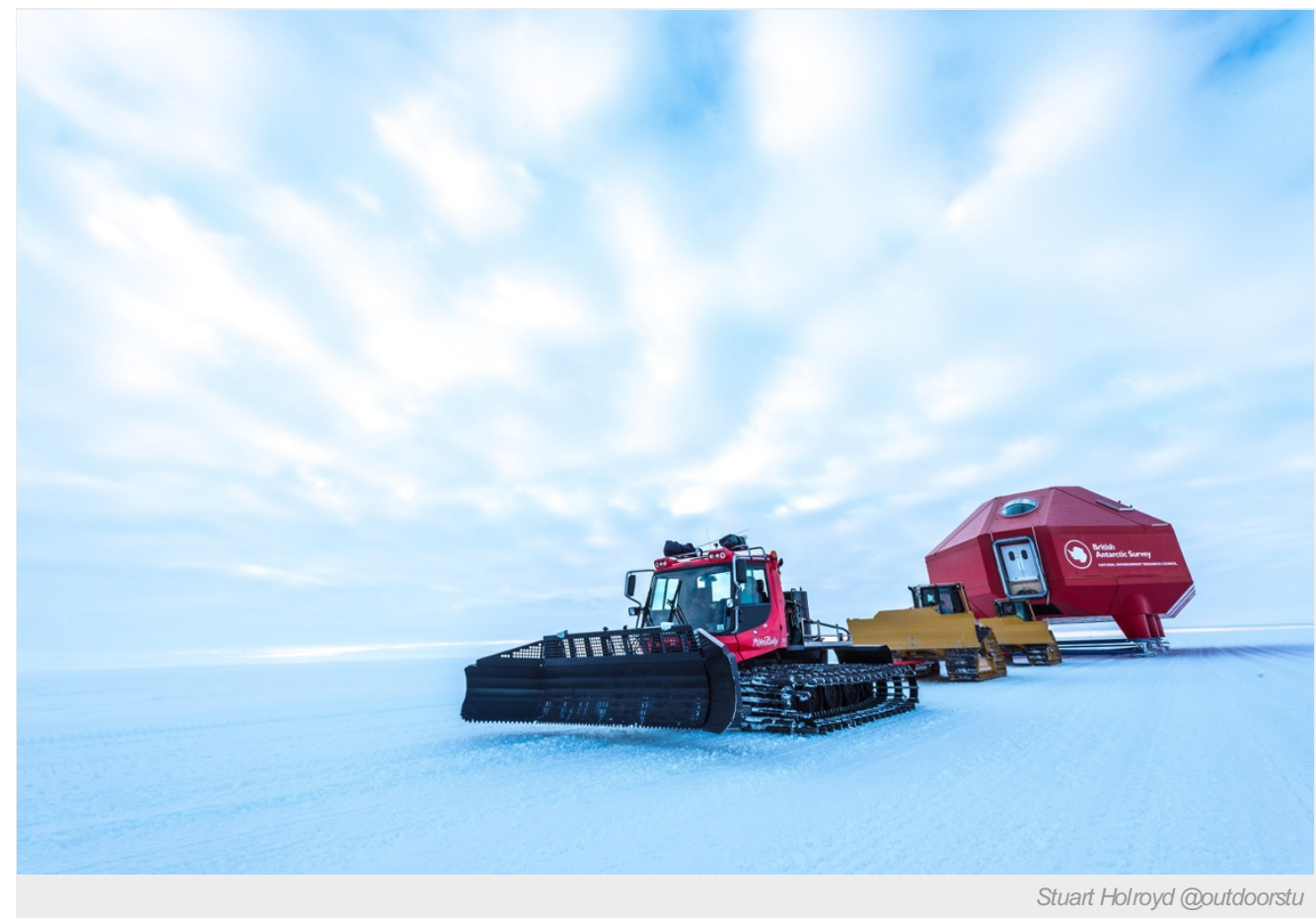

The British Antarctic Survey's Halley VI Research Station sits on the Antarctic ice and was designed to be movable. It is being relocated 23 kilometres away from its previous site because of a growing crack in the shelf on which it rests. But the survey announced on 16 January that it will evacuate all its staff from the base over winter owing to concerns over another crack that has opened nearby; the survey is taking measures to ensure that this will not harm planned scientific data collection.

\section{Starfish swirls}

This video of water movements around an eight-week-old starfish larva won William Gilpin of Stanford University, California, and his colleagues first place in the Nikon Small World in Motion Photomicrography Competition, announced in December. Also in December, Gilpin and his colleagues reported in a paper in Nature Physics ${ }^{1}$ how these observations can offer insight into these animals' lives and explain how starfish balance swimming and feeding. 


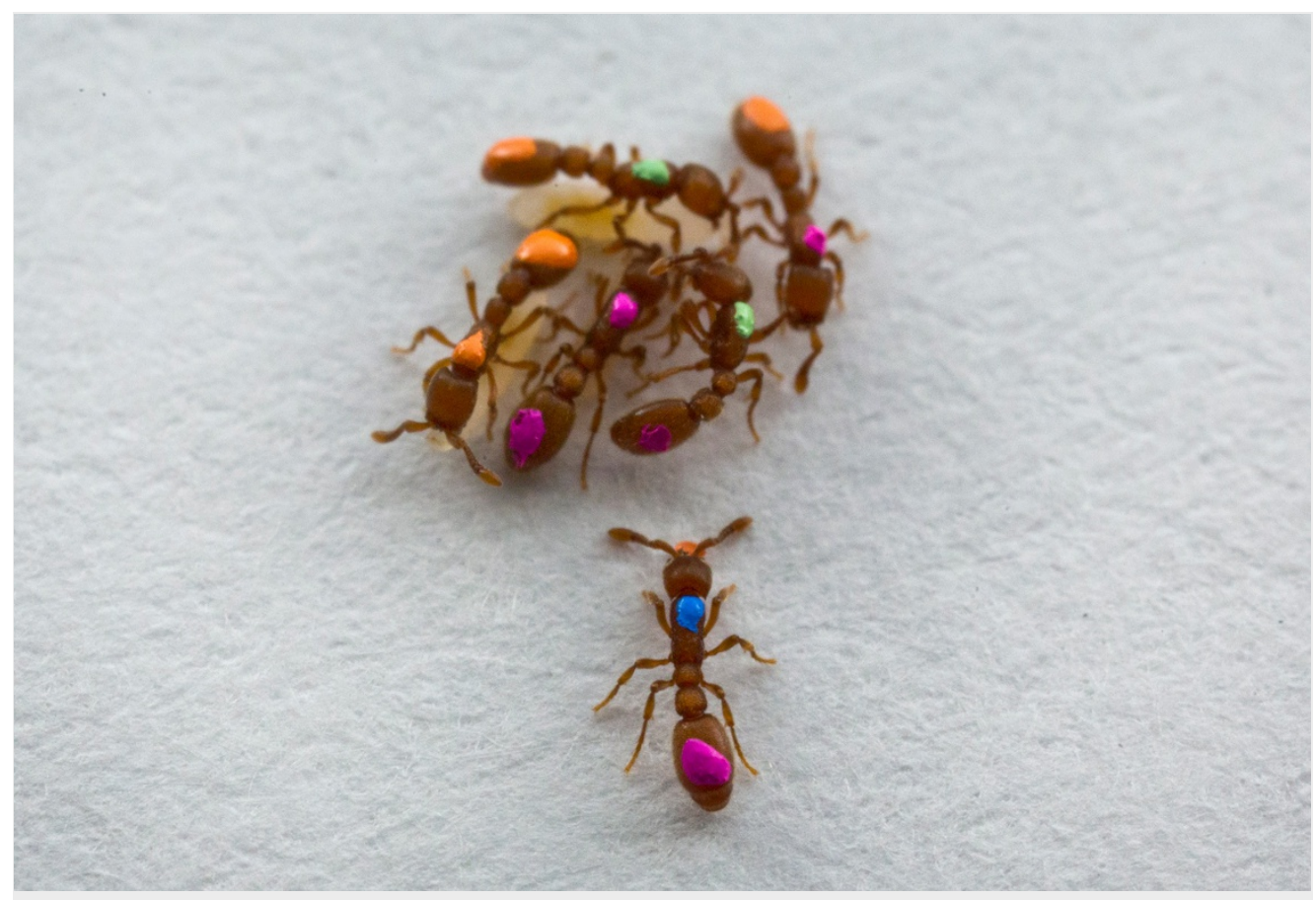

Beatrice de Gea/The New York Times/eyevine

Ant researchers struggle to distinguish their experimental animals, and so sometimes resort to colourcoding them with paints. These insects at the Rockefeller University in New York City are part of a project that aims to unpick the behaviour of ants.

\section{Touchdown!}

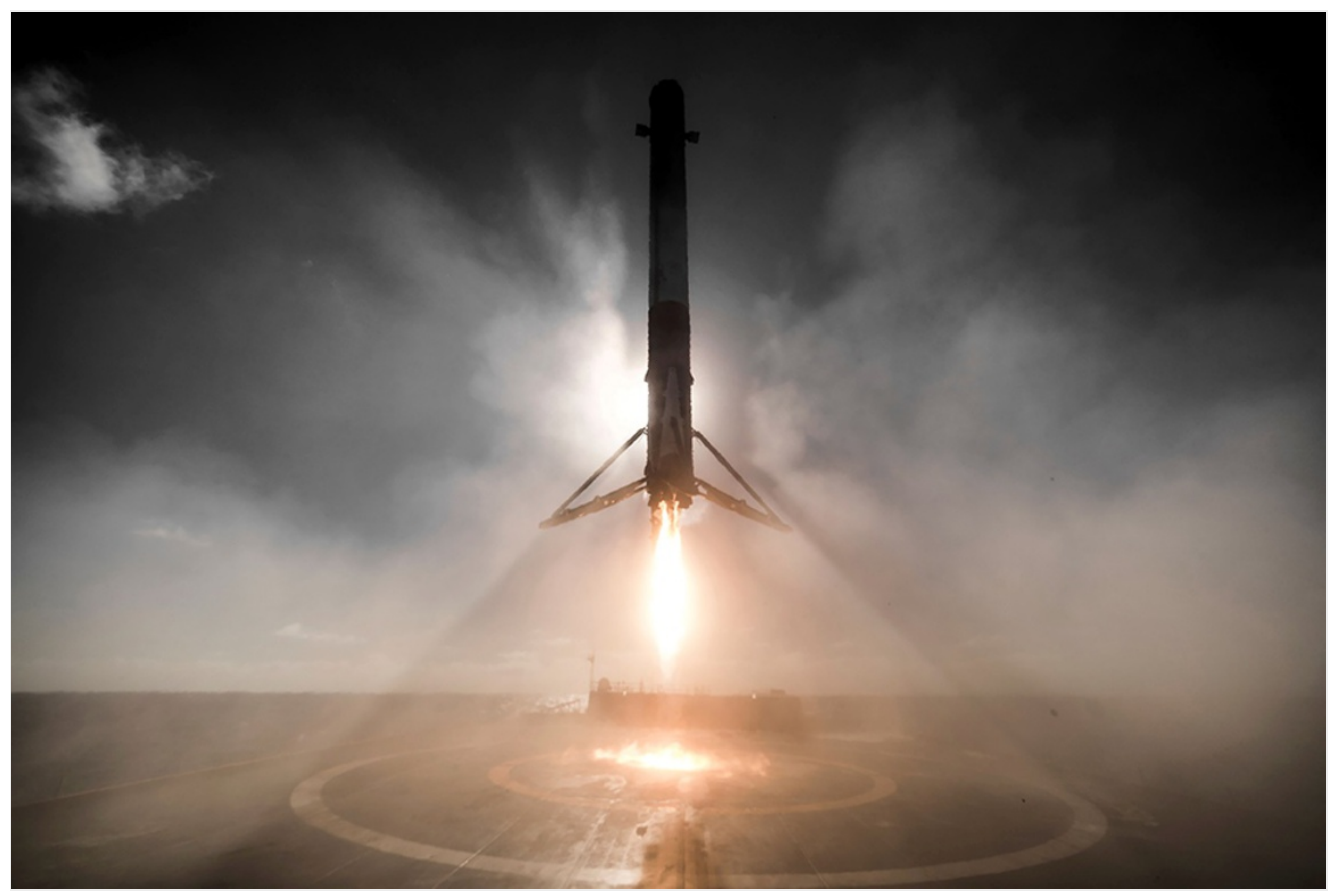

SpaceX

Pictures of fiery rocket launches are common, but this one is unusual. It's a rare shot of SpaceX successfully landing one of its reusable rockets on a ship in the Pacific. The vessel is named 'Just Read the Instructions', after an intelligent spaceship in a novel by lain Banks.

\section{Cold snap}




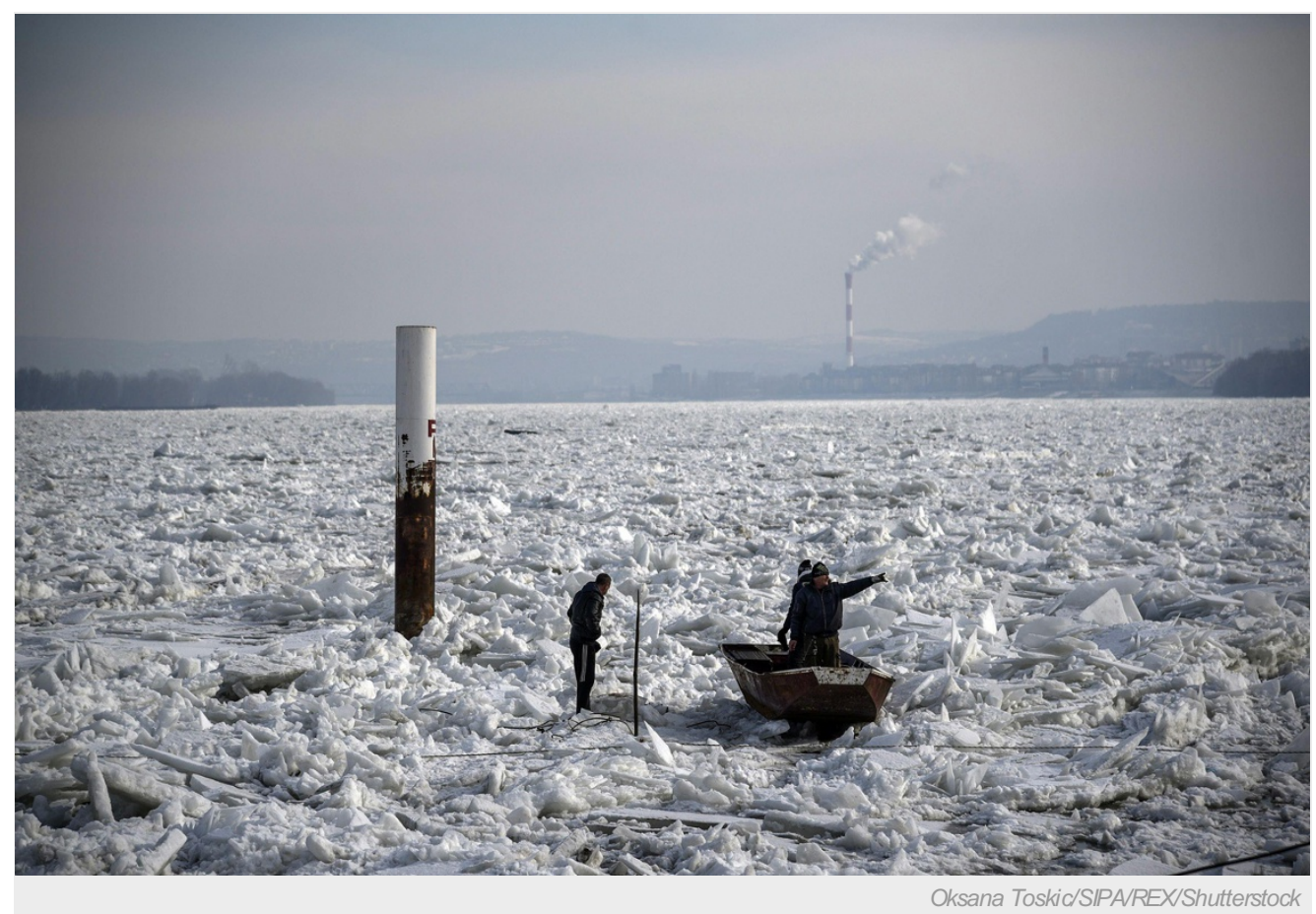

Severe weather in Serbia this month froze the Danube river in Belgrade.

\section{Ultraviolet flowers}

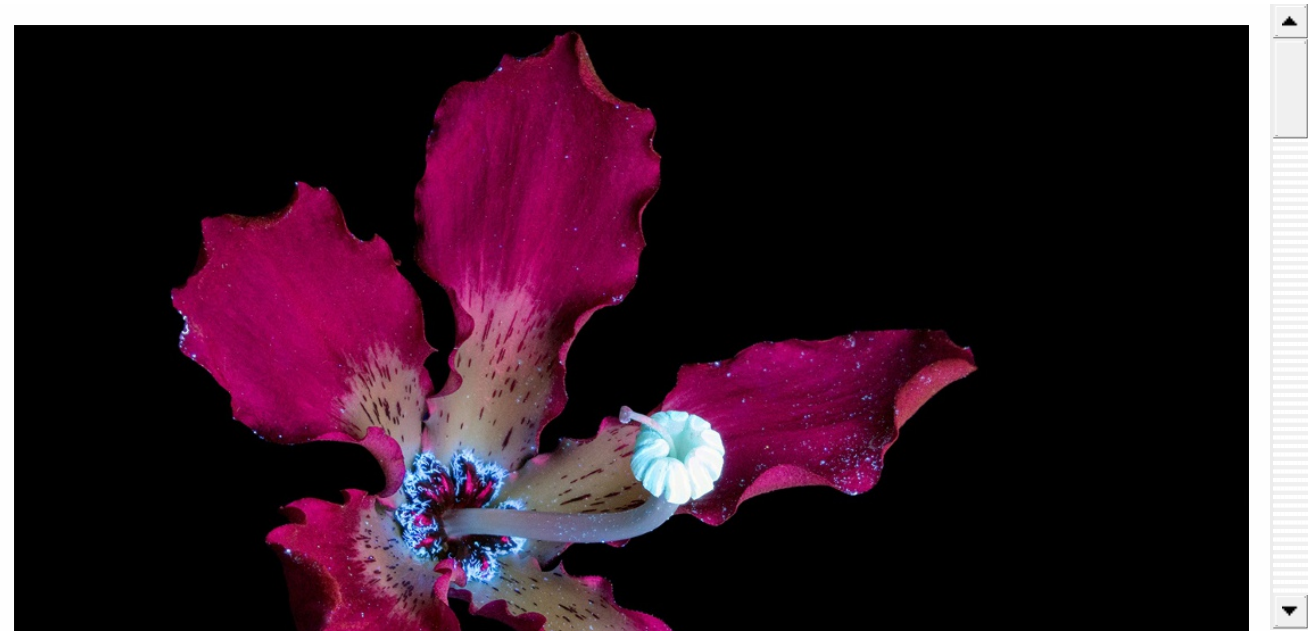

\section{Blooming marvellous}


Blooms II - John Edmark

John Edmark

Artist John Edmark creates 3D-printed sculptures, which create strange animations when spun. This work is based on the 'golden ratio', a mathematical pattern seen in many natural systems, such as plant branching and some shell spirals.

Nature | doi:10.1038/nature.2017.21386

\section{References}

1. Gilpin, W., Prakash, V. N. \& Prakash, M. Nature Phys. http://dx.doi.org/10.1038/nphys3981 (2016). 